\title{
Influencing factors and knowledge gaps on anemia prevention among female students in Indonesia
}

\author{
Lafi Munira, Pramon Viwattanakulvanid
}

College of Public Health Sciences, Chulalongkorn University, Thailand

\begin{tabular}{l} 
Article Info \\
\hline Article history: \\
Received May 24, 2020 \\
Revised Dec 27, 2020 \\
Accepted Jan 22, 2021 \\
\hline
\end{tabular}

\section{Keywords:}

Anemia prevention Female high school students Iron tablet

Knowledge

\begin{abstract}
Adolescents (10-19 years old) are at high risk of developing iron deficiency anemia. Prevalence of anemia in young women in Indonesia was $37.1 \%$ which increased to $48.9 \%$ in 2018 , with the proportion of anemia in the age group of 15-24 years and 25-34 years. The objectives of this study were to understand the influencing factors and gaps of knowledge related anemia prevention among female high school students. A qualitative case study design was conducted (April-May 2020) among nine female students (15-18 years old) from two senior high schools in Banjarmasin, Indonesia. Sampling technique used in this study was purposive sampling. Registered student who has total study period in the school not less than six months and students who refused to participate in this study were excluded. Data collection was used focus group discussion via WhatsApp messenger video call. Data analysis was mixed between content analysis and thematic analysis. Female students admit that they lack the initiative to find out about anemia. With the lack of understanding about anemia, the female students admitted that they did not really know whether preventing anemia was an important thing to do. The anemia education program at schools needs to enhance the female student's knowledge about iron tablet consumption.
\end{abstract}

This is an open access article under the CC BY-SA license.

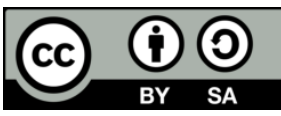

\section{Corresponding Author:}

Pramon Viwattanakulvanid

College of Public Health Sciences

Chulalongkorn University

Institute Building 2-3, Soi Chulalongkorn 62, Phyathai Rd, Pathumwan, Bangkok 10330, Thailand

Email: pramon.v@chula.ac.th; ukhtilafi@gmail.com

\section{INTRODUCTION}

Anemia is a condition with the low levels of hemoglobin in the blood due to few red blood cells and or a small amount of hemoglobin in each cell. There are many types of anemia but iron deficiency is the most common type. Iron deficiency anemia is one of the most common nutritional disorders in the world [1]. Anemia is a public health problem found throughout the world that affects up to 1.62 billion sufferers or about a quarter of the world's population in both developed and developing countries. More than $50 \%$ of global anemia cases are due to iron deficiency [2]. Symptoms of anemia according to it are usually not typical and often unclear such as pale, easily tired, palpitating, and shortness of breath. while according to and symptoms/signs of anemia include fatigue, lethargy, weakness, fatigue, neglect, pale lips, shortness of breath, slippery tongue, increased heart rate, difficulty defecating, decreased appetite, sometimes dizziness, and sleepy [3-5].

The impact caused by anemia occurs in impaired physical and psychological development, decreased physical work and income, decreased resistance to fatigue, increased morbidity and mortality. Anemia suffered by adolescent girls can cause decreased learning achievement, decreased endurance so it is 
susceptible to infectious diseases. In addition, in anemic adolescent girls, their level of fitness will go down which impacts on low productivity and sports performance and not achieving maximum height because at this time there is a peak in height growth $[6,7]$.

The main factors causing iron deficiency anemia include inadequate food intake, and the presence of absorption and increased need for iron and excessive iron loss, genetic defects, diseases that affect blood cells and blood cell producing organs such as malaria, schistosomiasis, helminth infections mining and HIV infection [8]. Factors such as socioeconomic, biochemical, and anthropometric are known to be associated with low levels of hemoglobin in the blood. These factors can be decisive in relation to iron, including education level, income level, body mass index (BMI), parasitology, gender, and seasonality. Previous research has shown that other dietary components are also risk factors for anemia when intake of protein, vitamin $\mathrm{A}$, folic acid, vitamin $\mathrm{C}$, and vitamin B12 is inadequate [9].

Adolescent is defined by World Health Organization as a person between 10 and 19 years of age. The world is home to 1.2 billion individuals aged 10-19 years [10]. Adolescents (10-19 years old) are at high risk of developing iron deficiency anemia due to an increased need for accelerated but poor food intake, high infection rates, and worm attacks and the consequences of early marriage and pregnancy in adolescents. Anemia can have profound negative impact on psychological and physical development, healing capacity, work performance, and reproductive health of an individual [11]. The consequences of iron deficiency are reduced attention, memory and school performance in adolescents, reduced attendance of their schools, retention of physical growth, emergence of menarches, decreased immune status and morbidity from infection, decreased physical capacity and work performance, increased fetal morbidity and mortality, increasing perinatal risk for mothers and neonates, the incidence of low birth weight, increasing overall infant mortality [12].

The World Health Organization (WHO) aims to reduce the prevalence of anemia in reproductive age women by 50 percent by 2025 [13]. Based on Indonesia National Basic Health Survey in 2013 prevalence of anemia in young women was $37.1 \%$ which actually increased to $48.9 \%$ in 2018 , with the proportion of anemia in the age group of 15-24 years and 25-34 years. These things clearly reinforce that adolescent health is crucial for the success of health development, especially in the effort to print the quality of the nation's future generations [14].

In 2015 in the province of South Kalimantan, from 17,239 adolescent girls it was found that 5,021 suffered from anemia, in other words the prevalence of anemia in adolescent girls in South Kalimantan in 2015 was $29.13 \%$. This shows that the prevalence of anemia adolescents in South Kalimantan is higher than the target set by the government in 2010, namely the target of decreasing the prevalence of anemia in adolescents to 20\% [15]. Anemia survey in 2014 in Banjarmasin prevalence nutritional anemia in adolescent girls reaches $42.42 \%$. Banjarmasin is an urban area that has many schools. In 2018, there are 40 schools that have been targeted by the government for anemia reduction programs. Several attempts have been made by the government through the health department to implement a program to check the levels of hemoglobin in the blood and iron tablets for students in junior high schools. According to data from the Department of Health in 2016 there were 603 female students who were anemia, in 2017 there were 1138 female students who were anemia, and in 2018 there were 884 female students who were anemia [16].

The problem of malnutrition in Indonesian young women is still very significant. Anemia can affect those women's physical health, hampering their study concentrations and decreasing their study performance at school. If a young woman chooses to become a mother, anemia can increase the likelihood of complications and fetal development problems. One of the efforts of the government and some private sectors was to implement the Weekly Iron Tablet Supplementation program. These Iron tablets contain iron and folic acid which are the initial components to pursue nutritional deficiencies. The goal, is to prepare young women so that when pregnant they are already well nourished. Thus, the cycle of malnutrition between generations can be decided. However, now the important major problem is compliance with Iron tablets consumption due to lack of information [17].

Regulation of the Minister of Health of the Republic of Indonesia Number 88 Year 2014 regulates the Standard for Increasing Blood Tablets for women of childbearing age and pregnant women. Food sources rich in iron and folic acid are generally found in animal protein sources such as liver, fish and meat whose prices are relatively expensive and are not yet fully affordable by most people in Indonesia. Giving iron tablets supplementation is one of the important efforts in the prevention and control of anemia which is an effective way because it can prevent and overcome anemia due to iron deficiency and/or folic acid [18].

The target of the Iron Tablets Supplementation program is female students aged 12-18 years at school, by giving this tablet one tablet every week throughout some period of time. Iron Tablets Supplementation are not given to female students who suffer from diseases, such as thalassemia, hemosiderosis, or on the indication of other by the doctors. Unfortunately, now the biggest problem is compliance with Iron Tablets consumption due to the lack of information. For this reason, government 
provides the information materials needed by midwives, health workers, and also school to convey the importance of this pill [18].

The success of the prevention and response program approach on anemia is very dependent on active community participation based on careful analysis of behavioral changes in the form of assessment of knowledge, attitudes and practices that exist in the community. This study used KAP (Knowledge, Attitude and Practice) theory on health education. "KAP theory" is a health behavior change theory, proposed by western scholars in the 1960s, in which the changes of human behavior are divided into three successive processes: the acquisition of knowledge, the generation of attitudes and the formation of behavior. The theory presents the progressive relationship among knowledge, attitudes and behavior as follows: knowledge is the foundation of behavior change, and belief and attitudes are the driving force of behavior change. "Health belief model" was put forward in the 1950s, which pointed out that the formation of health belief played a key role for people to accept the persuasion, change the bad behavior, and adopt the healthy behavior [19]. Behavior change is strongly influenced by knowledge which is an important domain for the formation of one's actions. Knowledge is the result of sensing from vision and hearing obtained from various sources, among others through health workers [20].

However there is a limitation from previous studies related to measure knowledge, attitude, and practice on anemia prevention among high school female students in Indonesia. By identifying the important influencing factors related to anemia prevention practice, we will understand more about knowledge, attitude and practice of female high school students towards anemia prevention then providing informations to create suitable programs to school and local health district to improve awareness and participation of female high school students towards anemia prevention. This study results can be used as important information for local government and schools to conduct suitable programs to increase female student knowledge, attitude, and practice on anemia prevention. This study results can be used as baseline data for other researchers to conduct intervention study based on knowledge, attitude, and practice on anemia prevention. The objectives of this study were to understand the influencing factors and knowledge gaps of anemia prevention among female high school students.

\section{RESEARCH METHOD}

A qualitative case study design was conducted (April-May 2020) among nine female students (1518 years old) from two senior high schools in Banjarmasin, Indonesia. Sampling technique used purposive sampling. Data collection of this qualitative study used focus group discussion among nine participants. Registered student who have total study period in the school not less than six months and students who refused to participate in this study were excluded. Instrument used in this study such as focus group discussion guidelines, online application platform for tele-interview (Whatsapp Video Call), internet connection, audio tape recording, notes, transcript of interviews. Validity methods used in this study were triangulation statement, researcher self-asked questions, and researcher iterative process. Data analysis were mixed between content analysis, thematic analysis and grounded theory. Ethical approval given by Ethics Review Board, Faculty of Public Health, University Muhammadiyah Jakarta: No.10.005.B/KEPKFKMUMJ/IV/2020.

\section{RESULTS AND DISCUSSION}

Anemia reduction education programs have been conducted in the middle of 2019 by Banjarmasin District Health Office through some senior high schools in Banjarmasin. They also checked Hemoglobin level of female's students at that time. From the discussion with the female students, we found that they received the anemia reduction program by the health workers. The health workers given the information related on anemia to the students. However, the previous anemia education at school was in the mid-2019. There is no additional information or education program regarding anemia prevention given to the students after the mid-2019. Female students admitted that they did not understand the benefit of anemia prevention and they also admit that they did not understand about anemia effects on their health and how to prevent anemia.

\footnotetext{
"Lately, there has been no education about anemia..." (Student-1)

"The previous anemia education program was at mid-2019, the anemia education program was given by health worker." (Student-2)
}

Blood deficiency is a term for anemia that is understood by students. Students did not have an understanding of why anemia can occur. From the discussion finding that female students perceived that 
dizziness was one of the sign of anemia. But this condition of dizziness not fully understand as sign of anemia. Female students stated that dizziness was not necessarily assumed as anemia symptom. Female students perceived that dizziness were also common condition that could overcome by taking headache relief medications. Female students feel unsure that preventing anemia is important because they do not received education about preventing the anemia and why it is important.

"I'm not sure last time what kind of information about anemia that already given, about the sign of anemia maybe something like dizzy, I've never felt the dizziness sis." (Student-3)

"I know if anemia is lacking blood, that's all. Maybe like feeling dizzy like that, I've never felt the sign of anemia." (Student-4)

"I don't know what causes anemia" (Student-1)

"I think anemia were lack of blood due to lack of hemoglobin throughout the body, isn't it?" (Student-6)

"The sign of anemia were dizzy, weak, I know that because my friends are like that, they have anemia." (Student-3)

"I never take medicine Sis, I don't feel that I'm anemic, so I think I don't need to take that iron tablet." (Student-4)

"I Just know the sign of anemia sis, something like dizziness maybe... But I think people are sometimes confused because they do not know they are really anemic or not if they experienced dizziness, so sometimes I think if I got dizziness, I just took the painkiller, and I'm not sure at that time I was anemic or not sis." (Student-7)

"Sis, I have heard that anemia can cause death, is it true sis?, So I know that anemia is dangerous." (Student-2)

Anemia reduction program that conducted in mid-2019 in Banjarmasin, Indonesia included hemoglobin level checked and also short education about anemia towards 350 female students in Banjarmasin, Indonesia. This program needs to be evaluated, because female students as subject of the intervention program admit that they did not understand much about anemia prevention and also they feel unsatisfied because they did not know the results of hemoglobin level checked. The female students also showed their disappointment to the program, because the teachers asked them to take iron tablets every week without details explanation what is the benefit of taking iron tablets, in the other hand the female students want to know the results of hemoglobin level checked.

"Yes, they took our blood, but we don't know the result, teacher just asked us to take that tablet every week...” (Student-1)

"Yes, we want to know why we should take the iron tablets sis, many people don't want to take it because they were not given an explanation Sis, we were taken our blood but we were not told the results Sis whether we are anemic or not, so we were only told to take that iron tablets ..." (Student-2)

Indicators of the success of the anemia program in schools so far have only relied on the results of blood samples before and after the iron tablet intervention. The program is said to be successful if the proportion of anemic students after getting an iron tablet intervention decreases compared to before getting an iron tablet intervention. But it seems there are things that still need to be considered from the implementation of this anemia reduction program. The provision of iron tablets on a regular basis without being balanced with the provision of education about anemia routinely and comprehensively is something that needs to be improved from the iron tablet delivery program at schools. Giving tablets without accompanied by massive information about anemia makes students feel unconvinced. The female students hope that they know more about the tablets that are given, as well as what benefits will be obtained when they consume these tablets.

Considering the ascending trend of anemia our country, it is essential to perform models for behavioral changes, then it should be noted that educating the public about preventive behaviors and lifestyle changes associated with anemia is greatly needed [21]. The results of some studies show that the nutritional has reduced the prevalence of diseases such as anemia in many European, North America, Japan and Australia countries [22]. Therefore, dietary recommendations with implementation of nutrition education programs, is necessary to reduce anemia among adolescent girls [23]. Given the importance of the role of schools in the field of education, nutrition education programs are raised in schools as a way to intervene in order to increase nutritional knowledge [24]. The health belief model (HBM), is one of the main models to train preventive behaviors. Educational interventions can be designed and implemented in order to prevent 
diseases using HBM [25]. The existence of such stimuli can trigger to act as a guide and stimulus (cues to action), and the individual feel adequacy in order to overcome the barriers (self efficacy) [26].

Female students admit that they lack the initiative to find out what anemia is even from the internet. With an understanding that is still lacking in relation to anemia, the female student admitted that they did not really know whether preventing anemia was an important thing to do. Given the iron tablets every week by the teacher caused confusion among students, because they did not know why they should always consume iron tablets every week, and also what is the benefit of taking iron tablets. A half-understanding makes students hesitate to drink iron tablets given by the teacher every week. They claimed that in the end they never took the iron tablets given, some of them discarded the iron tablets because they felt the side effects of nausea and the desire to vomit after consuming the iron tablets, while others claimed that they brought the iron tablets home but were not taken after arriving at home.
"I give it to my classmate, usually lack of blood so give it to a friend." (Student-4)
"I have checked Hemoglobin, my Hemoglobin was 15, so I think I don't need to take iron tablet." (Student-8)
"I don't know why are teacher suddenly told to take the iron tablets, and no one took it in the class because I don't know what it is for, my friends also didn't take it, most of the students were discard the iron tablets sis..." (Student-3)
"Yes, we want to know what the medicine is for sis, many people don't want to take it because they are not explained sis, we have blood drawn only we are not told of the results sis, so we are told to take medicine." (Student-2)

From this findings, we can assure that lack of knowledge was the important influencing factor that contributed to female student's action for not taking the iron tablets properly. The gaps of knowledge found in this study were related to the symptoms of anemia, the cause of anemia, the effect of anemia on their health, the benefit of taking iron tablet, and the provision of anemia prevention. Due to the lack of knowledge and the gaps of knowledge, female students perceived that they might be not at risk, this perception lead to their action for not taking iron tablets provided at school properly.

Previous study in Palestine related to improvement in knowledge, attitude and practice of iron deficiency anemia among iron-deficient female adolescents after nutritional educational intervention. The study aims to evaluate the effectiveness of a nutrition education intervention in iron deficiency anemia on the knowledge, attitude, and practice (KAP) among iron-deficient Female adolescents in the Gaza Strip. In this intervention study, 89 female adolescents aged 15-19 were recruited and randomly divided into intervention and control groups. Both groups received iron supplementation (ferrous fumarate $200 \mathrm{mg}$ ) weekly for three months. The female adolescents' knowledge improved significantly after a nutrition education intervention. Attitude and practice also improved respectively. Nutrition education intervention has an impact on improving knowledge, attitude and practices of iron-deficient female adolescents compared with control. The nutrition program should be adopted and integrated into comprehensive intervention programs to target Iron Deficiency Anemia among adolescents at various levels in Palestine [27].

Previous study in Iran found related to knowledge, attitude and practice of secondary school girls in Qazvin on iron deficiency anemia. The study population consists of 218 students who were randomly selected form ten secondary schools in a selected area. The results also showed that the field of education, the level of education, age, fathers' job and mothers, job had significant relation with knowledge. There is significant relationship between knowledge and attitudes. It was found that knowledge had significant relationship with practice [28]. From previous study found that individuals who had better nutrition knowledge had a more positive attitude towards eating healthier foods [29]. Conversely, poor knowledge is one of the risk factors to develop malnutrition [30]. Regarding the important role of schools in the education area, the implementation of nutrition education programs in schools is the way to intervene in order to enhance nutritional knowledge among students [25].

Knowledge is a very important domain for action someone. If the acceptance of new behavior is based on knowledge, awareness and a positive attitude, then the behavior will be lasting. Conversely, if not based on knowledge and then awareness won't be immediate for long [31]. Nutrition education intervention has an impact on improving knowledge, attitude and practices of iron-deficient female adolescents compared with control. The nutrition program should be adopted and integrated into comprehensive intervention programs to target IDA among adolescents at various levels in Palestine [27]. There is significant relationship between knowledge and attitudes. It was found that knowledge had significant relationship with practice Previous study determined the effect of educational program based on precede pattern on knowledge, attitude and nutritional performance related to iron deficiency anemia, the results showed statistically significant increase in mean score of knowledge, attitude (predisposing factors), training classes, participation in 
educational programs and the use of educational resources (enabling factors), encourage teachers and parents and peers (reinforcing factors) and performance of the experimental group compared to the control [32]. During COVID-19 situation, we faced many challenges, include the way to run data collection for research. Normally, we conduct face to face interview and build a good rapport with informants. Researcher decided to use tele-interview by video call as one of solution for focus group discussion in this new normal situation. By using video call, researcher could see participants face expression and build a rapport whether the feelings between real face to face and virtual face to face is quite different. In new normal situation, we also need to learn tele-interview techniques, to find the way how to make participants feel comfortable and convenient in discussion. From this research findings, we can obtain a better understanding about the important influencing factors and also the gaps of knowledge on anemia prevention among female students in Indonesia. This research findings can be used as baseline research that can be developed by further research studies with quantitative method.

\section{CONCLUSION}

Lack of knowledge is the important influencing factor on anemia prevention practice. Giving tablets without accompanied by massive information about anemia makes students feel unconvinced. The female students hope that they know more about the tablets that are given, as well as what benefits will be obtained when they consume these tablets.

\section{ACKNOWLEDGEMENTS}

This study is part of thesis that supported by Graduate School, AEC Scholarship Batch 1/2019 and CU Graduate Thesis Grant 2/2563, Chulalongkorn University.

\section{REFERENCES}

[1] B. Abalkhail and S. Shawky, "Prevalence of daily breakfast intake, iron deficiency anaemia and awareness of being anaemic among Saudi school students," International Journal of Food Sciences and Nutrition, vol. 53, no. 6, pp. 519-528, 2002, doi: 10.1080/09637480220164370.

[2] R. A. Alzaheb and O. Al-Amer, "The Prevalence of Iron Deficiency Anemia and its Associated Risk Factors Among a Sample of Female University Students in Tabuk, Saudi Arabia," Clinical Medicine Insights: Women's Health, Jan. 2017, doi: 10.1177/1179562X17745088.

[3] Arisman, Nutrition in the Life Cycle Handbook. Jakarta: Medical Book ECG, 2004

[4] Ministry of Health, Nutrition Anemia Management Guidelines for Young Women and women of reproductive age. A Guideline, Ministry of Health Republic of Indonesia, 1998.

[5] Supariasa, Nutritional Status Assessment Handbook. EGC: Jakarta, 2002.

[6] Ministry of Health, Nutrition Anemia Prevention Program for Fertile Age Women, A Guideline. Ministry of Health Republic of Indonesia, 2003.

[7] WHO, Guidelines for The Control of Iron Deficiency in Countries of The Eastern Mediterranean Middle East and North Africa, 1996

[8] J. A. Margwe and A. M. Lupindu, "Knowledge and Attitude of Pregnant Women in Rural Tanzania on Prevention of Anaemia," Afr J Reprod Health, vol. 22, no. 3, pp. 71-79, 2018, doi: 10.29063/ajrh2018/v22i3.8.

[9] M. R. Marques, et al., "Risk and Prevalence of Anemia among Women Attending Public and Private Universities," Ecology of Food and Nutrition, vol. 54, no. 5, pp. 520-528, 2015, doi:10.1080/03670244.2015.1037442.

[10] N. Angadi and A. Ranjitha, "Knowledge, attitude, and practice about anemia among adolescent girls in urban slums of Davangere City, Karnataka," International Journal of Medical Science and Public Health, vol. 5, no. 3, 2016, doi: 10.5455/ijmsph.2016.2007201570.

[11] L. Bandyopadhyay, et al,"Intervention for improvement of knowledge on anemia prevention: A school-based study in a rural area of West Bengal," International Journal of Health \& Allied Sciences, vol. 6, no. 2, pp. 69-74, 2017, doi: 10.4103/ijhas.IJHAS_94_16.

[12] WHO, Prevention of Deficiency Anaemia in Adolescents, A Guideline, 2011.

[13] WHO, WHA Global Nutrition Targets 2025: Anaemia Policy Brief, 2014.

[14] Ministry of Health, Indonesia, National Data of Health Survey. Statistics Report. Ministry of Health Republic of Indonesia, 2018.

[15] Ministry of Health, Indonesia, Banjarmasin District Health Office Data. Statistics Report, Ministry of Health Republic of Indonesia, 2015.

[16] Ministry of Health, Indonesia, Banjarmasin District Health Nutrition and Reproductive Departement Health Data. Statistics Report, Ministry of Health Republic of Indonesia, 2019.

[17] N. Soleiman and N. Abbaszadeh, "Relationship Between Anaemia, Caused from the Iron Deficiency, and Academic Achievement Among Third Grade High School Female Students," Procedia - Social and Behavioral Sciences, 2011, vol. 29, pp. 1877-1884, doi: https://doi.org/10.1016/j.sbspro.2011.11.437.

Int J Eval \& Res Educ, Vol. 10, No. 1, March 2021: 215 - 221 
[18] Ministry of Health, Nutrition and Reproductive Health Data, Statistics Report, Ministry of Health Republic of Indonesia, 2019.

[19] Y. Fan, et al., "Development and psychometric testing of the Knowledge, Attitudes and Practices (KAP) questionnaire among student Tuberculosis (TB) Patients (STBP-KAPQ) in China," BMC Infectious Diseases, vol. 18, no. 1, p. 213, 2018.

[20] S. Notoatmodjo, Health Education and Behavior Handbook. Jakarta: Rineka Cipta, 2003.

[21] M. Saffari, D. Shojaeizadeh, A. Heydarnia, and A. Pakpour, Health Education \& Promotion. Sobhan Press. Tehran: 9-38, 2009.

[22] J. Sadeghifar, et al, "Educational Intervention on Knowledge, Attitude and Practice (K.A.P) on Girl Students (high school) in Baneh City about Iron Deficiency Anemia in 2008-2009," Jundishapur Journal of Health Sciences, vol. 4, no. 2, pp. 39-46, 2010.

[23] M.M. Ahmad, L. A. Dardas, and H. Ahmad, "Cancer prevention and care: A national sample from Jordan," Journal of Cancer Education, vol. 30, no. 2, pp. 301-11, 2015.

[24] Ghajari H., Ghaderi N., Valizadeh R., Shakerinejad Gh, and Haghighizadeh MH., "Knowledge, Attitude and Nutritional Behavior of Female High School Students about Consumption of Calcium-Rich Foods in Khorramshahr City, South West of Iran," Int J Pediatr., vol. 4, no. 11, pp. 3837-46, 2016.

[25] K. Glanz, et al., Health behavior and health education: theory, research, and practice, 4th ed. San Francisco: Jossey-Bass, 2008.

[26] D. Kapur, KN. Agarwal, and DK. Agarwal, "Nutritional anemia and its control," Indian J Pediatr, vol. 69, no. 7, pp. 607-16, 2002.

[27] M. Jalambo, et al., "Improvement in Knowledge, Attitude and Practice of Iron Deficiency Anaemia among IronDeficient Female Adolescents after Nutritional Educational Intervention," Global Journal of Health Science, vol. 9 , no. 7, pp. 15-23, 2017, doi: 10.5539/gjhs.v9n7p15.

[28] D. Shojaeizadeh, "A Study on Knowledge, Attitude And Practice of Secondary School Girls in Qazvin on Iron Deficiency Anemia," Iranian Journal of Public Health, vol. 30, no. 1-2, 53-56, 2001. [Online]. Available: https://www.sid.ir/en/journal/ViewPaper.aspx?ID=33488.

[29] MC. Garcia-Lascurain, et al., "Effect of a Nutrition Education Program on NutritionRelated Knowledge of Englishas-Second-Language Elementary School Students: A Pilot Study," Journal of Immigrant and Minority Health, vol. 8, no. 1, pp. 57-65, 2006, doi: https://doi.org/10.1007/s10903-006-6342-9.

[30] E. Ryoo, “Adolescent nutrition: what do pediatricians do?" Korean Journal of Pediatrics, vol. 54, no. 7, pp. 287-291, 2011, doi: https://doi.org/10.3345/kjp.2011.54.7.287.

[31] S. Notoatmodjo, Health Education and Behavior Handbook. Jakarta : Rineka Cipta, 2003.

[32] S. Fathizadeh, et al., "The Impact of Health Education Based on PRECEDE Model on Knowledge, Attitude and Behavior of Grade Nine Female Students about Iron Deficiency Anemia in Qazvin," Jof health Ardabill, vol. 7, no. 3, pp. 321-30, 2016. 